\title{
Editorial to accompany the discussion paper 'Survival models and health sequences' by Walter Dempsey and Peter McCullagh
}

\section{Niels Keiding ${ }^{1}$}

Received: 14 June 2018 / Accepted: 15 June 2018 / Published online: 30 June 2018

(c) Springer Science+Business Media, LLC, part of Springer Nature 2018

The Lifetime Data Analysis Interest Group (of the American Statistical Association) was formed in 2014 with LIDA Editor Mei-Ling Ting Lee as a central initiator and founding chair. Its first independent conference took place at the University of Connecticut in May 2017 with Mei-Cheng Wang as chair.

As member of the program committee for that conference, I proposed that a discussion session be included, featuring the important development in 'reverse time'survival analysis by Peter McCullagh and Walter Dempsey and so far disseminated mainly by word of mouth.

I am grateful for the support this idea had from the authors, the conference organizers, and the Editor of LIDA, which had no strong tradition for publishing Discussion Papers.

I was lucky to get consent from several leading experts in the area to act as Discussants of the paper, with Per Kragh Andersen and Gary Chan giving invited oral contributions at the conference, joined by David Oakes at the spot, while Jack Kalbfleisch and Hans van Houwelingen based their invited commentaries on the written version of the paper.

I am grateful to all authors for their serious contributions which were always delivered on time and to Editor Mei-Ling Ting Lee and the Springer editorial staff for implementing the practical procedures for this new feature of the LIDA journal.

Niels Keiding

nike@sund.ku.dk

1 Section of Biostatistics, University of Copenhagen, P.O. Box 2099, 1014 Copenhagen, Denmark 